Vol. 3, No. 2, 2016

UDC 640. 43

M. Olikhovska

Ph.D in Economics, Associate Professor

Lviv Institute of PJSC "Interregional Academy of Personnel Management"

\title{
MODERN DEVELOPMENT OF THE SECTOR OF RECREATIONAL SERVICES IN TERMS OF EUROPEAN INTEGRATION OF UKRAINE
}

\begin{abstract}
The term "recreation" is specified, given the different concepts and theories, and its economic nature is identified. The basic economic parameters and functions of recreational services are highlighted. The relationship of recreation with material production and industrial infrastructure is substantiated. Structural elements of the recreation system functioning are formed, their main tasks in the modern period of state development are identified.
\end{abstract}

Keywords: recreation; recreation theory concept; recreation system; concept of human potential development; tourism; service sector; green tourism.

\section{Formulation of the problem}

Social production reforms, the changing nature of work, increased free time, improvement of ecological situation, and many other processes determine the large scale of recreation development. Thus in the consumption pattern of residents of industrialized countries, expenditures on recreation and education are $18 \%$ higher than those on buying food and 2.3 times higher than expenditures on the purchase of clothing and footwear [1]. Recreation belongs to the needs, which are impossible to refuse of.

According to O. Beidyk, recreation is a necessary condition of life, a kind of stress compensator. Reproduction of population efficiency is a rather new area of interdisciplinary research (economic, geographical, sociological, mathematical, medical and others). The category "recreation" is very popular in the regional economy. In the scientific literature several interpretations of the term can be found. Sometimes the concept "recreation" is identified with the term "recovery"; other scientists identify it with the concept "rest". Besides, the term is used to characterize the sector of national economy, which is related to the development of the territory for rest, treatment (rehabilitation) and tourism aimed at personal development, recreation, treatment, and improvement [3].

\section{Analysis of recent research and publications}

An important contribution to the research into formation and development of recreational services sector were made by such foreign scholars as I. Endzhejchyk, 2003 [12], V. Kvartalnov [15], 1998, V. Saprunova, 1998, [18], M. Sokolova, 2002 [19] and others. The historical aspects of recreation and tourism development are highlighted in the works of such domestic scientists as L. Dyadechko, 2007 [11], T. Tkachenko, 2009 [20], V. Fedorchenko, 2002 [21] and others. However, the investigation of the modern recreational services sector requires clarification and specification of the term "recreation"; it also needs selection of the main parameters and substantiation of its main constituents.

The purpose of the research is specification and definition of the term "recreation", the selection of its basic economic parameters and functions, as well as substantiation of the structure and objectives of the modern domestic recreation system.

\section{Presentation of the main material}

Current understanding of recreation is significantly different from the original meaning (recreation - entertainment, rest, change of actions). In the research presented in theoretical works of P. Hudz, recreation is defined, firstly, as an individual and household activities in the form of recreational cycles of certain duration, secondly, as the business of recreational enterprises, the purpose of which is to provide recreational services to customers and receive profit. The scientist points up that, according to their functional activities, the activities in such spheres as leisure, entertainment, culture, tourism, health-resorts, social sphere and environmental protection are referred to as recreation [7].

The conducted analysis of the scientific literature allows distinguishing the political and 


\section{Olikhovska}

economic, medical and biological, activity-based, geographical, technical and economic, anthropological and ecological concepts of the theory of recreation. Due to the existence of different definitions of the concept of "recreation", the scope of the analysis also changes.

According to theoretical research of the scientists working in this area, in some cases the development of certain types of recreational objects is analyzed, in other cases the operation of certain subsystems is examined, and still in other ones the state and prospects of a specified part of recreational facilities and resources are determined. Although the definition of recreation in the research literature is greatly differentiated, all researchers come from the fact that this concept describes consciously created general conditions that ensure the population efficiency reproduction.

The increasing role of the general conditions of the recreational sector organization has become the main point for its extensive study. During the last decade in scientific literature there is expressed an opinion about the nature of recreation that natural landscape conditions and material things should be referred to recreation. On the basis of the above said, recreation should be understood as the holistic natural object, the functioning of which creates general conditions of social and economic development. The objects, functioning of which creates the general conditions of social reproduction and social activities should be included to recreation. Moreover, the constituents of these objects are variable. With the course of social development these constituents are being constantly changed and supplemented, because the role of the general conditions increases.

V. Pavlov specifies such basic social functions of recreation as biomedical, sociocultural, economic and political [17]. The scientist states that in the economic group the reproduction of labor takes the main place. Recreation also saves socially necessary time and is a form of demand for services, which determines the formation of other sectors of economic activities.

In the scientific research the process of specification of the term "recreation" continues. However, it is methodically clearly revealed that it refers to the material elements, which create the conditions for the effective operation of the social aspects of life and natural landscape conditions. Recreation also includes the objects of accommodation in the private sector, catering services, consumer tourist services, transportation, communications, health care, physical culture and sports, education, culture and art, which are aimed to meet the needs of tourists, support their vital activities, spiritual and intellectual development.

It is important to note that there are many similarities between the concepts of "recreation" and "service sector", they have, for example, the same functional purpose, that of public services. But at the same time, there are differences: the service sector is an industry division, while recreation is a territorial approach to its development. In the works of researchers of this field there is no single definition of these categories, the process of specifying their structure and functions continues. But, none of these categories replaces one another.

In our opinion, recreation also performs economic functions, including expansion of the employment sector; acceleration of certain territories economic structure development; impact on the people's money expenditures, growth of foreign tourism and foreign currency inflow.

V. Pavlov makes similar conclusions, highlighting the following economic parameters of recreation:

- recreation belongs to the non-production sector, but includes production (e.g. tableware production etc.). The economic effect of recreational activities is felt in health care, rest and tourism institutions, as well as at the level of the country's national economy in the growth of gross national product;

- recreation is closely related to the natural environment, it develops at the intersection of economy and social sphere and ecology. Therefore, while determining the effect from the development of recreational activities along with economic factors the environmental and social factors should be also taken into account;

- economic parameters are closely related to the sort of the recreational resource and, therefore, to the economic characteristics of the recreational area conditions. This relationship is expressed by a system of indicators (potential capacity of recreational areas, cost of medical resources for one man-day, load and recreational capacity of the resort area, level of comfort) [17]. 
Focusing on the economic parameters of recreation, we believe that one more parameter should be added:

- recreation, namely tourism, can be considered as a form of human capital development, i.e. human intellectual, sensitive, cognitive efforts, which are aimed to acquire new social experiences.

Of great interest is the issue of recreation types classification and construction of its structural models. Recreation division into separate units allows exploring its role in socio-economic development of regions and, thereby, identifying its impact on the expansion and efficiency improvement of the region's economic activities.

While doing research into the place of recreation in the socio-economic development of regions it is necessary to study all its components. As O. Hulych notes that the increased attention to recreational areas is caused by the overall deterioration of the environment and depletion of natural resources, which encourage organizing and conducting the economic activities that are based on the sustainable environmental management, being environmentally friendly and contributing to the social and economic development of the region while complying with environmental standards [8].

P. Hudz complements with the similar statement. He believes that recreation, performing its reconstructive function, has, as the object of recreation, first of all, a human throughout his/her life cycle - from birth to transition to other dimensions rather than a human as part of workforce, and, secondly, a human as the natural heritage [7].

The authors consider the classification of recreational services differently; in particular, they differently substantiate their division criteria.

In his research, V.Kutsenko emphasizes that recreation remains in constant relationship with material production sphere and industrial infrastructure. This relationship has versatile character. Sociologists say that stratification in society is developing. Thus while outlining the social characteristics of a stratum and stratification they put a person, his/her interests and needs and their comprehensive quality satisfaction in the center [16]. Exactly this shows the social nature and the character of functioning of each stratum as well as the place of recreation in it.
Along with this, I. Berezhnaya notes that economists follow the principles used in the division of the economic sector - material production or non-production areas, i.e. recreation is classified according to the role of its individual units in creation of the social product [4]. Thus, recreation relates to the production sphere and its final product is production of services.

As to classification proposed by specialists of economic sphere, it should be noted that distinction and reference of recreation only to the production sphere, in our opinion, is inappropriate because all recreation institutions are also related to the social infrastructure.

As it is known, the concept of human development is based on four basic principles, which reflect productivity, equality, sustainability and person's life-capacity empowerment. The concept of human development is alternative to the view, which reduces development exclusively to economic growth. Economic growth and the increase in recreational services use are not seen as an end in itself but as a means of achieving goals of human development by means of tourism. Tourism allows getting benefits in competition with its rival under certain conditions. Tourism prevents emotional collapse of modern man, who lives at an accelerated rhythm.

M. Birzhakov notes that tourism acts as a sphere delivering services of psychological relief and reproduction of new sensory-emotional sides of man's inner world. Tourism is a necessary way to develop intellectual, sensory, cognitive efforts aimed at gaining new social experiences [5].

Along with this, in classification of recreation services O. Beidyk distinguishes Green Tourism and considers it to be a collection of objects, which create conditions for rest and recreation of society in the countryside. He refers private recreation institutions, organized on the basis of private housing, to green tourism. In his opinion, green tourism objects should be isolated in a separate group, as they are different from other types of recreation [3].

Today the category "green tourism" is very common in the scientific literature, although different authors give it an ambiguous interpretation.

We believe that green tourism should be understood as a system of organizations, businesses and services that deal with specialized servicing of 


\section{Olikhovska}

tourists in the countryside. We think that services, which ensure efficient operation, repair and reproduction of recreational objects, tourists' transportation means and others, should refer to the service system. In particular, it must also include: transport, communications, housing, repair services, auto-technical and information services. On this basis, tourist and recreational services can be divided into production (objects and constructions), social (residents and staff) and institutional (information services) parts.

For example, V. Kalytyuk notes that with the account of specific features of the regional recreational resources use, recreation should be divided into two major components:

- constant (based on health centers);

- temporary (based on the objects that are not included in the official recreation process) [14].

In our opinion, organization of these two kinds of recreation differs substantially; in particular, the elements that form the recreational system are complex structures, such as:

- natural resources and conditions;

- technical infrastructure;

- social subsystem.

Given this, the control system coordinates the activities of individual components and the systems in general, providing optimal conditions for their effective functioning.

The proposed classification of recreation does not purport to be exhaustive or having no alternative. Each section of recreation contains the components that are combined together by functional purpose. Thus, the communal recreation component comprises the sphere of everyday life, catering, trade. In our opinion, its main function is to meet communal and natural physiological needs of tourists.

The component of the engineering construction and environmental protection combines gas, electricity, water supply and drainage, roads, environmental protection (introduction of the system of control over sanitary conditions of villages, compliance with sanitary norms and rules of management). The social component of recreation should combine culture and art, places of worship, healthcare, physical education and sport. Its function is to develop and meet the cognitive and spiritual needs of tourists, protection and strengthening of health. The main tasks of the structural elements of recreation are presented in Fig. 1.

Communal, engineering construction and environmental protection, as well as social components of recreation belong to life support systems, which are developing according to the requirements of nowadays. The functioning of new forms of recreation contributes to the development of the sphere of paid services and therefore increases the tourists' demands to their quality. Here, the role of science grows and its integration with recreation increases.

It should be noted, that the opportunities and needs of the region in the areas of recreation depend on the number of tourists, i.e. the attractiveness of the region. Due to the large range of principles underlying organization of recreation in the region, it is important to find the optimal ways, which will be determined by a number of factors of organizing the recreation. The need for recreation areas is closely related to the number of tourists, the nature of recreation objects and the terms of usage of recreational facilities.

In conditions of socio-economic transformations in Ukraine the principles of recreation areas development have radically changed. This brought in some peculiarities in the formation of recreational systems of regions in general.

In M. Habrel's opinion, given the presentday realities, the role of temporary recreation objects increases. These objects are to be understood as the objects near the centers of gravity that meet the intended purposes of recreation, which can be implemented using objects or sites. The places for temporary rest are divided by the period of their usage into short stay (1 night), medium-term stay (up to 4 days) and long-term stay (over 4 days) [6].

The principle of zones' organization is closely related to the research of this issue. It suggests introducing a variety of areas, including facilities for parking, with the possibility of extremely short stay of tourists, with differentiated payment, depending on the stay duration and so on. Thus, the tourists' stay duration is the main criterion in determining the area capacity and substantiating opportunities of servicing a complex of objects. 


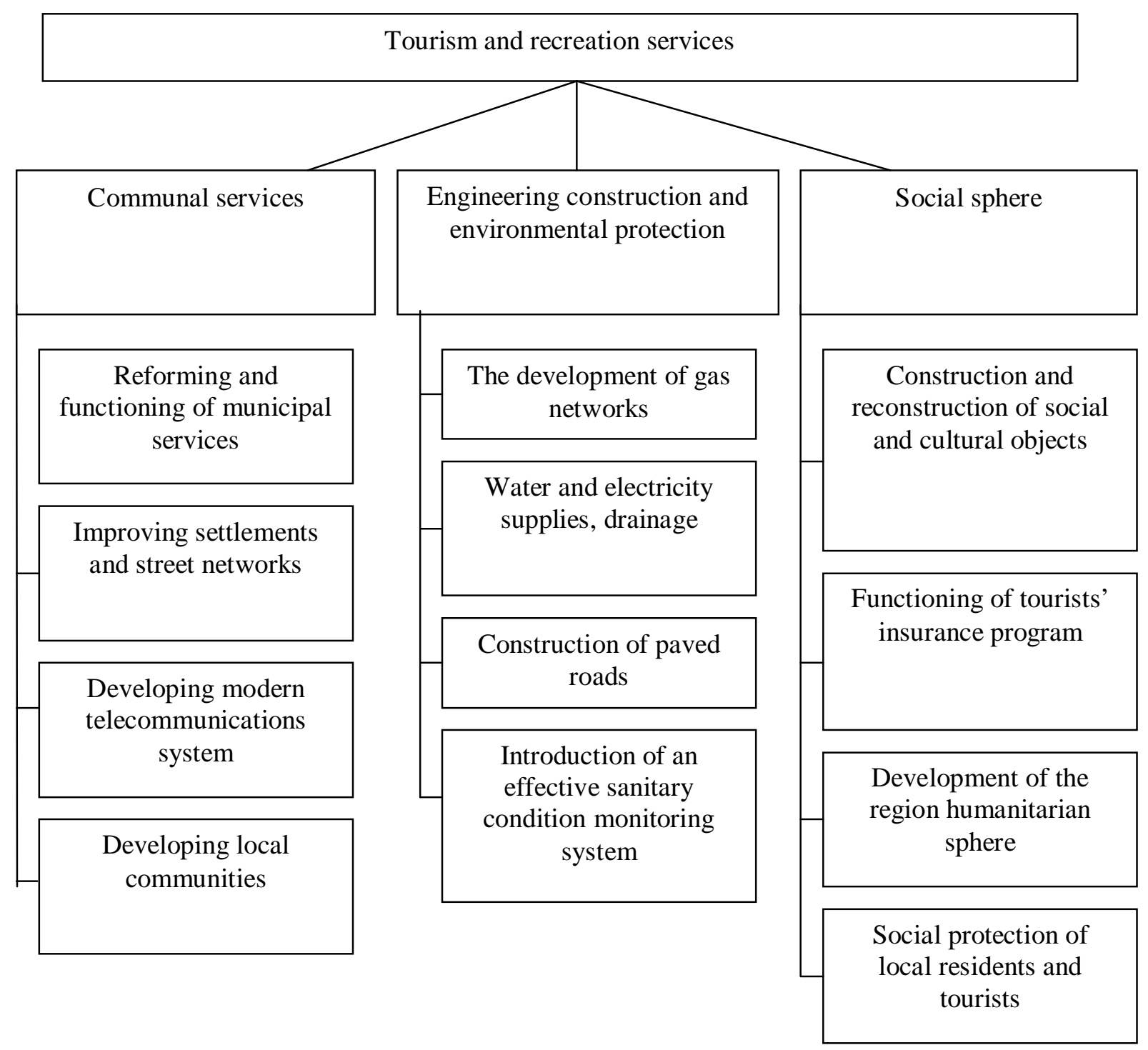

Fig. 1. The main tasks of the structural elements of tourism and recreation services

Note: formed by the author

R. Ivanukh and V. Zhuchenko note that recreational and tourist institutions are divided into private, departmental and combined [13]. We believe that this criterion is a key factor in determining the overall regional strategy of recreation system development because the assessment of patterns of recreation sites by the type of ownership will enable better attraction of investment. As the analysis of practices shows, the ownership affects the efficiency of using recreational institutions; in particular, a private object is more often used only by one owner, and this reduces the efficient use of space. In contrast, departmental and combined properties of the institution enable the possibility of using it in a combined mode.

M. Dolishnii in his studies classifies the objects of recreation by their capacity into small (50 seats), medium (50-100), big (100-250), large (250-500), larger (over 500) [9]. It is interesting that the capacity of an object affects the choice of architectural and planning solutions. On the basis of regulations, it is the object capacity that specifies the place of the object in a particular area and defines the distance to the residential buildings, utilities and so on.

It should be noted that the cost of land is very different and depends on the conditions of the 


\section{Olikhovska}

land plot. This greatly affects both the recreational system development and the features of each recreation object individually, depending on its location. Thus, high cost of land in the areas close to the protected complexes and unique landscapes should activate building on these lands of elite recreation facilities. That is, differentiation in the cost of land should lead to deepening the impact of this factor on the formation of the recreation system.

It may be concluded that in some cases the indicators of the regulatory norms are not adhered to; this concerns at least the interaction of organized and unorganized recreation, short-term and long-term stay. The reason for this, first of all, may be the lack of arranged areas suitable for temporary rest.

Similar conclusion is made by O. Dudkina, who notes that the distribution of the recreational places in different zones primarily depends on the balance of territories belonging to certain administrative districts and village councils. In particular, the regions that are situated far from the railway are more inclined to contain places of short-term rest [10]. Therefore, forecasting the recreation system development, the functional zoning of the entire region and districts should be taken into account.

We agree with the opinion of the scientist that for temporary rest there can be used both organized and unorganized areas. In particular, there is a clear pattern of allocation, in which in the peripheral regions the areas of short rest are grouped around specific recreational objects, and as we approach the center of recreation zones the capacity of individual objects decreases with the increase of total capacity (by increasing their number) and there is observed replacement of the addressed service to complex one [10]. It should be also noted that the development of recreation has a distinctly territorial character and it ensures the development of a particular area or organizes its communication with other regions.

Conclusions and perspectives for further research. Thus, recreation is the system of organizations and conditions for producing recreational services, which ensure the tourists' efficiency reproduction without worsening the living and working conditions of local residents.

Summarizing, we should note that recreation is one of the major priorities among modern social and economic issues. Given the significant social, economic and environmental effects, the recreational services sector has significant advantages and longterm prospects for the country during its economic restructuring and European integration.

Therefore, the key objectives of modern national recreation should be:

- improvement of social infrastructure development;

- formation of a system of servicing people and tourists with a wide range of high quality services as well as creation of new workplaces;

- prevention of further degradation of settlements and territories;

- environmentally sustainable development of the region.

In terms of emerging market relations there appears the necessity of forming and developing effectively working market of recreational services. It brings significant peculiarities to the formation of the recreational system of Ukraine.

\section{References}

1. Antonyuk, Ya. (2001). The sphere of consumer services for the public: the development status and principles of state regulation at the local level. [In Ukrainian].

2. Beznosyuk, V. D. (2001). Organizational-economic and information maintenance of development of a tourist-improving complex in regions of Ukraine. Master's thesis, Institute of Regional Research of the NAS of Ukraine, Ukraine. - Lviv. [In Ukrainian].

3. Beidyk, O. O. (2001). Recreational and tourist resources of Ukraine: methodology and methods of analysis, terminology, zoning. - Kyiv: "Kyiv university". [In Ukrainian].

4. Berezhnaya, I. V. (1997). The forms of organization and the methods of recreational sphere management in the new economic conditions (the case of Crimean region). Master's thesis, Institute of Economic and Legal Research of the NAS of Ukraine, Ukraine. Donetsk. [In Russian].

5. Birzhakov, M. B. (2000). Introduction into tourism. Saint Petersburg: Publishing house "Herda". [In Russian].

6. Habrel, M. M. (2000). Architectural and landscape research of recreation in the region. State and problems of information support. Materials of the International Congress: Problems of informatization of recreational and tourist activities in Ukraine: prospects of cultural and economic development. Truskavets. - Pp. 54-59. [In Ukrainian].

7. Hudz, P. V. (2001). Economic problems of resort and recreational areas development. Institute of 
Economic and Legal Research of the NAS of Ukraine. - Donetsk : LLC "Yuho-Vostok, Ltd". [In Ukrainian].

8. Hulych, O.I. (2007). Environmentally sustainable development of resort and recreational areas: theoretical and practical issues. - Lviv: Institute of Regional Research of the NAS of Ukraine. [In Ukrainian].

9. Dolishnij, M. I. (2000). The regional policy recreational potential development: principles of formation and implementation mechanisms. - Socioeconomic research during the transition period. Recreational industry: experience, problems and prospects of development (annual scientific papers of the Institute of Regional Research of the NAS of Ukraine), XXI, 7-13. [In Ukrainian].

10. Dudkina, O. P. (1999). Regional peculiarities of recreating zones' development (methodical, organizational and economic bases). Master's thesis, Institute of Regional Research of the NAS of Ukraine, Ukraine. Lviv. [In Ukrainian].

11. Dyadechko, L. P. (2007). Economics of tourism: schoolbook. Kyiv: Center of educational literature. [In Ukrainian].

12. Endzhejchyk, I. (2003). Modern tourism business. Ecological strategies in management of a firm. Moscow: Finance and Statistics. [In Russian].

13. Ivanukh, R., Zhuchenko, V. (1998). The strategic issues of development of recreational and tourist complex of Ukraine. Economics of Ukrane, 1, 65-70. [In Russian].
14. Kalytyuk, V. A. (1999). Recreational and tourist complex in the market economy. Lviv. [In Ukrainian].

15. Kvartal'nov, V, Romanov, A. (1998). International tourism: development policy. Moscow: Soviet sport. [In Russian].

16. Kutsenko, V. I. (1994). The sphere of health reproduction of the population (socio-economic and regional aspects). Kyiv: Scientific thought. [In Ukrainian].

17. Pavlov, V. I. formation of the regional market of recreational services. Materials of the International Congress: Problems of informatization of recreational and tourist activities in Ukraine: prospects of cultural and economic development. Truskavets. P. 32-34. [In Ukrainian].

18. Saprunova, V. B. (1998). Tourism: Evolution. Structure. Marketing. Moscow: Os'-89. [In Russian].

19. Sokolova, M. V. (2002). The history of tourism: schoolbook. Moscow: Masterstvo. [In Rusian].

20. Tkachenko, T. I. Sustainable development of tourism: theory, methodology, business realities. Kyiv: Kyiv National University of Trade and Economics. [In Ukrainian].

21. Fedorchenko, V. K. D'orova, T. A. (2002). The history of tourism in Ukraine. Kyiv: Vyshcha shkola. [In Ukrainian]. 